\title{
ARTIGO
}

dO https://doi.org/10.22481/praxisedu.v16i37.6405

\section{POLÍTICA DE FORMAÇÃO DE PROFESSORES E A DESTRUIÇÃO DAS FORÇAS PRODUTIVAS: BNC-FORMAÇÃO EM DEBATE}

\author{
TEACHER EDUCATION POLICY AND THE DESTRUCTION OF PRODUCTIVE \\ FORCES: BNC-TRAINING IN DEBATE \\ POLÍTICA DE FORMACIÓN DE PROFESORES Y LA DESTRUCCIÓN DE LAS \\ FUERZAS PRODUCTIVAS: BNC-FORMACIÓN EN DEBATE
}

\author{
Tiago Nicola Lavoura \\ Universidade Estadual de Santa Cruz - Brasil
}

Melina Silva Alves

Universidade Federal da Paraíba - Brasil

Cláudio de Lira Santos Junior

Universidade Federal da Bahia - Brasil

\begin{abstract}
Resumo: Por intermédio do debate teórico que busca explicitar a conjuntura de crise estrutural do capital e de destruição das forças produtivas, o artigo desenvolve uma análise dos fundamentos teórico-filosóficos e pedagógicos da atual Base Nacional Comum de formação de professores, conhecida como BNC-Formação. Argumenta-se que tais diretrizes curriculares articulam-se à política educacional mais geral de rebaixamento e esvaziamento dos currículos e do processo de formação humana impetrados pelos rumos da política brasileira nos marcos do desenvolvimento do capitalismo dependente, e sua subserviência ao ideário neoliberal, à reestruturação do setor produtivo e à financeirização do capital em sua fase imperialista. Em tempos de transição, advoga-se a necessidade de uma verdadeira resistência ativa, desenvolvida tanto no plano da dimensão pedagógica quanto política, com vistas à defesa de outra lógica de formação de professores cujo horizonte seja a busca pela humanização dos indivíduos e a superação do modo de produção da vida social regido pela exploração do trabalho pelo capital.
\end{abstract}

Palavras chave: Crise; Destruição das forças produtivas; Formação de professores.

\begin{abstract}
Through the theoretical debate that seeks to explain the conjuncture of structural crisis in capital and the destruction of productive forces, the article develops an analysis of the theoreticalphilosophical and pedagogical foundations of the current Common National Base for teacher training, known as BNC-Training. It is argued that such curricular guidelines are linked to the more general educational policy of lowering and emptying curricula and the process of human formation brought about by the directions of brazilian politics in the framework of the development of dependent capitalism, and its subservience to the neoliberal ideology, the restructuring productive sector and the financialization of capital in its imperialist phase. In times of transition, the need for real active resistance is advocated, developed both in terms of the pedagogical and political dimensions, with a
\end{abstract}


view to defending another logic of teacher education whose horizon is the search for the humanization of individuals and the overcoming of mode of production of social life governed by the exploitation of labor by capital.

Keywords: Crisis; Destruction of productive forces; Teacher education.

Resumen: A través del debate teórico que busca explicar la coyuntura de la crisis estructural en el capital y la destrucción de las fuerzas productivas, el artículo desarrolla un análisis de los fundamentos teórico-filosóficos y pedagógicos de la actual Base Nacional Común para la formación docente, conocida como BNC-Formación. Se argumenta que tales pautas curriculares están vinculadas a la política educativa más general de bajar y vaciar los currículos y el proceso de formación humana provocado por las direcciones de la política brasileña en el marco del desarrollo del capitalismo dependiente y su subordinación a la ideología neoliberal, a la reestructuración sector productivo y la financiarización del capital en su fase imperialista. En tiempos de transición, se aboga por la necesidad de una resistencia activa real, desarrollada tanto en términos de dimensiones pedagógicas como políticas, con miras a defender otra lógica de la formación docente cuyo horizonte es la búsqueda de la humanización de los individuos y la superación del modo de producción de vida social regido por la explotación del trabajo por el capital.

Palabras clave: Crisis; Destrucción de fuerzas productivas; Formación de profesores.

\section{Introdução}

$\mathrm{O}$ artigo pretende discutir a atual política de formação de professores implementada pela Resolução do Conselho Nacional de Educação (CNE) - Conselho Pleno (CP) n 02 de 20 de dezembro de 2019, intitulada de Diretrizes Curriculares Nacionais para a Formação Inicial de Professores para a Educação Básica, instituindo a Base Nacional Comum para a Formação Inicial de Professores da Educação Básica (BNC-Formação), relacionando-a com o quadro conjuntural de desmonte do ensino público superior instaurado pelo governo brasileiro de extrema-direita em meio à crise estrutural do capital em sua fase imperialista.

Partimos da compreensão de que o conjunto das medidas políticas que configuram o esvaziamento dos currículos na formação de professores e o desmonte do ensino público superior faz parte da totalidade da conjuntura nacional e internacional de intensos retrocessos político-econômicos, sociais e culturais em meio à crise estrutural do capital (MÉSZÁROS, 2009; MONTORO, 2016), culminando com um quadro generalizado de desmonte dos serviços públicos, de privatizações e de entreguismo do patrimônio nacional ao rentismo e ao capital financeiro internacional. 
A crise estrutural do capital impõe mudanças em escala mundial, destacando-se entre elas a propagação ideológica do ideário neoliberal, a reestruturação do setor de produção de mercadorias e a intensificação do processo de financeirização do capital.

Tais medidas apresentam como mote à lógica de como o capital se comporta para controlar esta crise, que incide, por meio de inúmeras mediações, na formação humana, já que a configuração de uma nova força de trabalho é necessária para dar sobrevida ao capital. Isso diz respeito tanto à adaptação direta às necessidades do setor produtivo quanto ao aprofundamento da alienação e desorganização da classe trabalhadora.

Assim, é por meio da compreensão dos nexos e relações entre a crise estrutural do capital e o desmonte da formação humana, considerando o processo de destruição das forças produtivas e as necessidades colocadas em períodos de transição do modo de produção, que realizamos a análise da atual política de formação de professores implementada em nosso país pela recém-aprovada BNC-Formação de Professores.

\section{A crise estrutural do capital e o processo de destruição das forças produtivas}

A formação humana em sua objetivação mais geral e a formação de professores em sua particularidade expressam, na conjuntura de crise estrutural do capital, o confronto de projetos antagônicos: um, unilateral, segundo os interesses do capital e outro na perspectiva da formação omnilateral ${ }^{1}$, nos marco da necessidade de superação do trabalho alienado. Por isso, a formação de professores apresenta como contradição fundamental de sua existência a luta entre capital e trabalho, podendo ser constituída a partir de pressupostos que aprofundem esta contradição ou de pressupostos que objetivem sua superação.

Considerando o movimento de desenvolvimento da contradição entre capital e trabalho, alçamos as categorias realidade e possibilidade ${ }^{2}$ como fundamentais para debater algumas determinações da crise estrutural do capital que incidem, a partir de mediações bem específicas, sobre a formação humana e a formação de professores. Destarte, reconhecer as determinações da formação humana nos permite disputar a sua direção para impulsionar as

\footnotetext{
1 Omnilateralidade ter a ver, em suma, com a perspectiva marxiana de máximas possibilidades de desenvolvimento humano, original e livre. Trata-se de uma conquista histórica, com a chegada do ser humano a uma totalidade de capacidades, tanto produtivas, quanto de consumo e de prazeres (MANACORDA, 2010).

2 É necessário diferenciar o real daquilo que é possível, compreendendo a dialética das transformações. Conforme Cheptulin (1982, p.338): “A realidade é o que existe realmente, e a possibilidade é o que pode produzir-se quando as condições são propícias [...]. A possibilidade tem uma existência [...] como propriedade, capacidade da matéria transformar-se [...] de um estado qualitativo em outro".
} 
suas contradições em meio à luta de classes, o que se apresenta como uma necessidade extremamente atual.

Neste sentido, entendemos necessário debater a hegemonização do capital mundial em sua fase superior, a fase imperialista (LÊNIN, 2005), e a entrada deste modo de produção em uma irreversível crise estrutural sócio-metabólica do capital (MÉSZÁROS, 2009) confirmando a tendência defendida por alguns autores marxistas, em especial Trotsky (2010a, 2010b, 2011), sobre a conversão das forças produtivas em forças destrutivas.

Tal tendência aponta que o desenvolvimento das forças produtivas atingiu um nível extremamente avançado no atual modo de produção, mas, devido às relações sociais de produção capitalista impedir a continuidade deste desenvolvimento, o capital passa a destruir as próprias forças produtivas, constantemente, para manter o seu processo de reprodução, o que inclui a destruição do próprio ser humano e de sua força de trabalho.

Neste sentido, a contradição entre as relações de produção e o desenvolvimento/destruição das forças produtivas apresenta-se como importante mediação da formação humana, encerrando limites e possibilidades.

A crise estrutural do capital é inerente ao sistema capitalista. Apresenta contradições indissolúveis e universais, ou seja, atinge a todas as esferas da vida. A crise que enfrentamos não se apresenta somente como crise política, mas é realmente uma crise cada vez mais profunda do capital. A solução mais exponencial do capital para ela são as guerras, notadamente, quando os métodos normais de expansão fracassam e, assim, faz com que o capital se defronte com seus limites absolutos. Mészáros (2009, p. 17) denominou a atual crise estrutural como crise estrutural de ordem sócio-metabólica do capital:

[...] a crise estrutural do sistema do capital como um todo - a qual estamos experimentando nos dias de hoje em uma escala de época - está destinada a piorar consideravelmente. Vai se tornar a certa altura muito mais profunda, no sentido de invadir não apenas as finanças globais mais ou menos parasitárias, mas também todos os domínios de nossa vida social, econômica e cultural.

Ela assume novas proporções e aprofunda-se em meados da década de 1970, com a crise do petróleo que culmina, também, com o esgotamento do welfare state - o estado de bem-estar social, concepção keynesiana de estado - e do modelo fordista/taylorista de produção implantados a partir da crise da superprodução de 1929.

O estado de bem-estar social consistiu em uma intervenção do estado - pós II Guerra Mundial - no processo econômico-social, a partir do desenvolvimento de políticas de 
assistência social, tais como o direito à saúde, educação e ao seguro-desemprego. Já o modelo fordista/taylorista de produção tem como base a racionalização das operações efetuadas na produção, a padronização, a repetição e a decomposição de tarefas em uma base de produção mais rígida, para desta forma evitar desperdícios e elevar a extração da mais-valia do trabalhador.

Ambos tiveram seu ápice após a II Guerra Mundial, no entanto, a denominada era de ouro do capitalismo (HOBSBAWM, 1995), que durou da recuperação pós-crise de 1929 à crise da década de 1970, passou a mostrar seus limites também nos chamados países de primeiro mundo, levando ao declínio a concepção keynesiana de estado. De acordo com Hobsbawn (1995, p. 203-204):

Hoje é evidente que a Era de Ouro pertenceu essencialmente aos países capitalistas desenvolvidos, que, por todas essas décadas, representaram cerca de três quartos da produção do mundo, e mais de $80 \%$ de suas exportações manufaturadas [...]. Apesar disso, a Era de Ouro foi um fenômeno mundial, embora a riqueza geral jamais chegasse à vista da maioria da população do mundo - os que viviam em países para cuja pobreza e atraso os especialistas da ONU tentavam encontrar eufemismos diplomáticos.

Desta feita, o neoliberalismo, a reestruturação produtiva e a financeirização do capital ${ }^{3}$ sobrevêm como resposta, um caminho para contornar a crise das décadas de 1970/80. O neoliberalismo, tanto no campo econômico quanto no campo político, tem suas principais premissas apresentadas por Hayek (1990). Seu livro lançado em 1944 ganhou o prêmio Nobel de economia em 1974.

A obra defende fundamentalmente a liberdade do mercado - livre circulação do capital - frente a qualquer tipo de intervenção estatal, denominando de 'caminho da servidão' o percurso da perda de liberdade, pois, a liberdade pessoal e política, para Hayek, só poderia ser atingida com o fim da intervenção estatal e a implantação do livre mercado. O neoliberalismo pauta-se, sobretudo, na defesa apologética da liberdade individual.

A ideologia neoliberal apresenta-se como hegemônica e dominante na atualidade, subsidiando sustentabilidade político-ideológica para as alterações necessárias ao processo de produção e reprodução do capital sendo, portanto nada mais do que uma expressão ideológica do capitalismo em sua fase imperialista.

\footnotetext{
${ }^{3}$ Vale afirmar que capital não é sinônimo de capitalismo. A forma capital, uma relação social, tem seu início na circulação de mercadorias, ainda no século XVI, período caracterizado por Marx (2006) de acumulação primitiva do capital.
} 
As premissas neoliberais pautam-se na defesa da concorrência como geradora de equilíbrio na sociedade - liberdade do mercado diante do estado e dos sindicatos, sendo estes também responsáveis pela crise econômica, já que atuam para pressionar o aumento dos gastos sociais com bens públicos e salários. A privatização dos bens públicos e dos serviços em geral acabaria por torná-los mercadorias a ser adquiridas com a 'liberdade' forjada pelo estado imperialista neoliberal. Isto posto, apresentemos com base em Lênin (2005, p. 90) os cinco traços fundamentais do imperialismo - base concreta da ideologia neoliberal:

1) a concentração da produção e do capital levada a um grau tão elevado de desenvolvimento que criou os monopólios, os quais desempenham um papel decisivo na vida econômica; 2) a fusão do capital bancário com o capital industrial e a criação, baseada neste "capital financeiro", da oligarquia financeira; 3) exportação de capitais, diferentemente da exportação de mercadorias, adquire uma importância particularmente grande; 4) a formação de associações internacionais monopolistas de capitalistas, que partilham o mundo entre si; e 5) o termo da partilha territorial do mundo entre as potências capitalistas mais importantes [...].

É importante reconhecer que Lênin desenvolveu esta caracterização do imperialismo como fase superior do capitalismo em 1917, quando a financeirização do capital ainda não predominava. Todavia Lênin, ainda no início do século XX, levanta o ponto fundamental da entrada do capitalismo em sua fase imperialista: a transformação da livre concorrência em monopólio, isto é, a eliminação da pequena produção, transformação da grande em outra maior e a concentração cada vez mais avassaladora da produção e do capital: "[...] os monopólios, que derivam da livre concorrência, não a eliminam, mas existem acima e ao lado dela. Engendrando assim contradições e conflitos de interesses particularmente agudos e intensos" (LÊNIN, 2005, p. 89).

Pode-se afirmar que as contradições são tão agudas na fase imperialista do capital que o monopólio, derivação da livre concorrência constitutiva antes da transição à fase imperialista, passa a determiná-la sem excluí-la, e por isso Lênin (2005) sustenta que a definição mais sintética que pode ser dada ao capitalismo em sua fase imperialista é a de capitalismo monopolista.

Já a reestruturação produtiva é orientada pela ideologia neoliberal e realizada com base no modelo toyotista de produção, que preconiza o just in time, ou seja, a produção de mercadorias de acordo com a demanda do mercado evitando, deste modo, a superprodução. Faz também parte do processo produtivo toyotista a flexibilização, a precarização e a instabilidade do trabalho. Ressalte-se que o advento do toyotismo é sustentando pelo 
desenvolvimento das forças produtivas que abrem a possibilidade de reestruturar a produção com base em novas tecnologias, permitindo reduzir postos de trabalho e manter as taxas de extração de mais-valia (ANTUNES, 2007).

Por fim, com relação à financeirização do capital, Foster (2009) afirma que as últimas quatro décadas pós-crise dos anos de 1970 são caracterizadas pela centralidade da financeirização do capital frente à produção real - o que se articula ao ideário neoliberal. O capital financeiro é a forma mais desenvolvida de circulação de capital. A financeirização não é crédito industrial - antecipação de capital como forma de adiantar a produção/reprodução do capital diretamente ao setor produtivo - mas, advém da evolução do sistema de crédito industrial, com a introdução de créditos de valorização do capital por meio do capital fictício.

Mollo (2011) explica que o capital real gera mais-valia a partir da exploração da força de trabalho. Já o capital fictício, que não é, mas, advém do desenvolvimento do sistema de crédito industrial, não apresenta relação direta com a produção real de mais-valia (mas depende dela). Trata-se, resumidamente, da valorização do capital no processo de circulação pela cobrança de juros de dívidas.

A crise da primeira década dos anos 2000 adveio justamente da quebra do capital financeiro. Impulsionada pela explosão da bolha imobiliária dos Estados Unidos da América (EUA), ela foi denominada de 'crise dos subprimes', nome dado ao crédito de risco do setor imobiliário dos EUA. No entanto, esta crise não se restringiu aos EUA, ela impetrou diretamente o setor produtivo e financeiro em escala mundial, pois o capital é a forma dominante das relações na sociedade capitalista e seu movimento de expansão não possui fronteiras.

Curiosamente, foi o estado novamente quem salvou a falência dos (grandes) banqueiros, objetivando a máxima de que, no neoliberalismo, o estado é mínimo, mas só para às necessidades dos trabalhadores, pois quando é preciso salvaguardar as grandes corporações e seus banqueiros, ele assume firmemente seu papel de sustentação.

Mesmo em tempos de financeirização global, o trabalho ainda se apresenta como a principal possibilidade de enfrentamento ao capital. Embora a relação hegemônica ainda seja de subsunção do primeiro pelo segundo, o capital permanece dependente do trabalho para se reproduzir. Uma importante forma encontrada pelo capital para enfrentar a resistência do trabalho foi por meio da implantação de tecnologias computadorizadas com novas formas de organização de trabalho, como a robótica, concretizando, dentre outras consequências, a destruição de postos de trabalho (ANTUNES, 2007; HARVEY, 2011). 
Desta maneira, tem-se no processo de desenvolvimento das forças produtivas a formação de um exército industrial de reserva, como forma de minar a organização dos trabalhadores que são obrigados a aceitar salários mais baixos para sobreviver. Por isso, o desemprego estrutural foi parte da doutrina neoliberal instaurada com grande força pelos governos Thatcher, Reagan e Pinochet (HARVEY, 2011).

Em suma, podemos afirmar que o atual modelo de produção imperialista em crise estrutural não separa progresso de destruição: ao mesmo tempo em que a ciência se desenvolve, uma parcela mínima da população a acessa, ou seja, a ciência evolui, no entanto, nunca estivemos tão próximos de sermos aniquilados pelo próprio extermínio do meio ambiente, pelo surgimento de novas doenças e pelo crescimento dos conflitos bélicos.

$\mathrm{Na}$ América Latina, a lógica de desenvolvimento do capitalismo estruturou-se pela objetivação do capitalismo dependente (FERNANDES, 1981). Enquanto na Europa se desenvolvia um modelo econômico autossustentado de dentro para fora com a apropriação das riquezas nas colônias e que forneceu sustentação à posterior expansão imperialista, na América Latina, a expansão do capital se desenvolveu na relação de expansão entre núcleos internos e externos, que reuniam (e ainda reúnem) o interesse de consolidação das burguesias locais, o que retirou da América Latina o caráter nacionalista das burguesias tal como nos países capitalistas clássicos.

É justamente a aliança de interesses comuns entre os polos internos e externos que possibilita a continuidade e, cada vez mais, um profundo desenvolvimento na América Latina do capitalismo dependente. Logo, de forma diferente da burguesia dos EUA e da Europa, a burguesia latino-americana cumpriu e ainda cumpre um papel antinacional, porque no contexto do desenvolvimento do capitalismo imperialista, ela consegue impor sua hegemonia localmente de maneira mais compensadora no formato de subserviência.

Por exemplo, a defesa da soberania nacional na América Latina não é atrativa à burguesia local, pois, tal defesa vai de encontro aos interesses da burguesia internacional, interesses esses com os quais a burguesia local se alia, ao reconhecer nestes a manutenção e expansão de seus próprios interesses. Esta relação, de acordo com Fernandes (1981, p. 54), desenvolve a "articulação estrutural de dinamismos econômicos externos e internos requer[endo] uma permanente vantagem estratégica do polo econômico hegemônico, aceita como compensadora, útil e criadora pelo outro polo".

É nesta convergência de interesses internos e externos que se explicita a relação de capitalismo dependente, uma relação de aliança importante tanto à expansão do capitalismo 
imperialista quanto à manutenção e enriquecimento da burguesia local. O capitalismo dependente e o capitalismo do 'tipo imperialista' são essenciais para a manutenção da hegemonia imperialista e para o próprio processo de reprodução do capital.

A monopolização do capital, o surgimento de oligarquias financeiras, e a partilha do mundo entre as potências capitalistas demonstram como é importante para o imperialismo a existência de países capitalistas dependentes e, também, a impossibilidade de existência de um capitalismo 'humanizado', como muitos autores defendem. Na medida em que as crises se aprofundam, o capital apresenta-se de uma forma cada vez mais incontrolável, o que leva a destruição das forças produtivas.

No Brasil, a situação política decorrente dos governos petistas de Luiz Inácio Lula da Silva e de Dilma Rousseff (sobretudo seu primeiro mandato) não alterou esse quadro de capitalismo dependente. Em que pese tais governos terem ampliado políticas de transferência de renda (mas não de distribuição, vide programas como Bolsa Família), de expansão do ensino público e maiores gastos nas áreas sociais, não houve ruptura de fato com a aliança de dependência existente entre a burguesia nacional e burguesia internacional.

Embora a política aplicada pelos governos do partido dos trabalhadores tenha alterado significativamente a realidade, sobretudo das camadas mais pobres e miseráveis, não mudou o estado das coisas. O Brasil continuou como um país subdesenvolvido, se concretizando uma sociedade que produz a miséria e se alimenta dela, conforme sustenta Frigotto (2013), tomando expressão emprestada do sociólogo Francisco de Oliveira.

O segundo mandato da presidenta Dilma Rousseff (2015-2016) foi interrompido por um golpe jurídico-parlamentar, e os governos que a sucederam, Temer e Bolsonaro, vêm tomando medidas sob a alcunha de conter a crise capitalista e a recessão, mas, cujos objetivos e resultados são a retirada de direitos dos trabalhadores e a diminuição dos gastos com áreas essencialmente necessárias à vida dos mais pobres, como demonstram os elevados cortes na saúde e educação ${ }^{4}$.

É no âmbito de toda esta conjuntura internacional e nacional que se tem dado o processo de destruição das forças produtivas, cujo processo de degeneração e desumanização da formação humana em termos de escolarização é uma de suas facetas.

\footnotetext{
${ }^{4}$ Vide a Emenda Constitucional 95/2016, conhecida como a "PEC da morte", promulgada durante o governo golpista de Michel Temer, congelando os gastos sociais por 20 anos. Uma dura política de austeridade fiscal, cuja consequência é a redução real dos investimentos em áreas sociais, resultando em cortes cada vez maiores nos investimentos necessários a manutenção da saúde e educação públicas, por exemplo.
} 
As taxas de analfabetismo, analfabetismo funcional e escolarização, por exemplo, são importantes indicadores da precária situação educacional em nosso país e da incidência da destruição das forças produtivas no campo educacional. Dados do último censo realizado no Brasil (2010) demonstram que os índices de analfabetismo são alarmantes, mesmo considerando seus percentuais de queda nas últimas décadas. Na década de 1940, 56\% da população era analfabeta, o que equivalia a um número absoluto de 23 milhões de analfabetos, considerando uma população de 41,2 milhões de pessoas.

Dados atuais indicam a existência de 18 milhões de analfabetos $(9 \%)^{5}$. O Nordeste permanece como a região do país com a maior quantidade de pessoas não alfabetizadas $(17,6 \%)$. A maior taxa de analfabetismo no país foi registrada em Alagoas $(22,5 \%)$. As demais regiões apresentaram, respectivamente, as seguintes taxas de analfabetismo: Norte $(10,6 \%)$, Centro-Oeste $(6,6 \%)$, Sudeste $(5,1 \%)$, Sul $(4,7 \%)^{6}$.

Em âmbito educacional, a crise se aprofunda e a subsunção do trabalho ao capital também se evidencia, como por exemplo, pela desvinculação e transposição da educação da esfera do estado para a esfera do mercado. Este desatrelamento demonstra como na sociedade capitalista neoliberal prevalece uma intensa valorização do sistema privado de educação e, ao mesmo tempo, evidencia um intenso movimento de precarização da educação pública, algo que Melo (2004) denominou de mundialização da educação ${ }^{7}$. Vale recuperar uma evidencia de Marx (2011, p. 669) sobre imputação da educação à forma de mercadoria:

A reprodução da classe trabalhadora envolve ao mesmo tempo a transferência e a acumulação de habilidade, de uma geração para a outra. O capitalista considera a existência de uma classe trabalhadora dotada de habilidade entre as condições de produção que lhe pertencem; vê nela a existência de seu capital variável.

O reconhecimento da educação como indispensável à preparação da força de trabalho, e desta como capital variável, nos permite discutir porque a educação e, sobretudo, a formação humana, na atual fase imperialista senil do capital, se relaciona diretamente com a inserção do trabalhador na sociedade, já que a força de trabalho deste trabalhador capacitada pelo processo educativo será vendida por ele mesmo como mercadoria.

\footnotetext{
${ }^{5} \mathrm{O}$ número absoluto inclui as pessoas com 10 anos ou mais de idade.

${ }^{6}$ As porcentagens incluem pessoas com 15 anos ou mais de idade. O senso não esclarece quanto ao número de analfabetos funcionais.

7 Esta expressão denota uma analogia à 'mundialização do capital' em oposição ao termo 'globalização' e apresenta como referência o processo de transformação global da educação em mercadoria, correspondendo ao movimento de insaciabilidade do capital.
} 
A superação do capital por uma sociedade que liberte as forças produtivas - o que inclui a força de trabalho - do entrave de seu desenvolvimento apresenta-se como necessidade, todavia, a passagem de um modo de produção a outro não se concretizará espontaneamente, pois, são os seres humanos os responsáveis por levar às últimas consequências este processo de mudança qualitativa. Nesse sentido, Trotsky (2011) contribui sobremaneira ao afirmar que é preciso impulsionar a superação do atual modo de produção por intermédio da transição, ou seja, da mediação entre a realidade e a possibilidade.

A possibilidade, alçada das contradições da realidade, assinala deste modo a tendência de que, progressivamente, o conjunto dos trabalhadores pode vir a apropriar-se da totalidade da produção humana material e espiritual, o que inclui o livre acesso às possibilidades formativas abertas pelo alto desenvolvimento das forças produtivas no capitalismo.

Portanto, se trata de um nível da realidade a ser impulsionado no âmbito da transição, socializando toda a produção humana no sentido pleno que possibilite desenvolvimento da humanidade em suas máximas potencialidades. É a partir desta lógica que Trotsky (2010a) defende que a elevação do patamar cultural da população aumentará na medida em que vivamos em uma produção cooperativa planificada com distribuição socializada.

Importa reconhecer que na análise de Trotsky (2010a, 2010b, 2011) sobre o atual estágio de desenvolvimento das forças produtivas, ao afirmar que as forças produtivas deixaram de crescer e converteram-se em forças destrutivas, não significa dizer que há uma estagnação na produção da técnica, da ciência, ou de outros campos de objetivações humanas, mas sim, de identificar que o desenvolvimento das forças produtivas não tem mais se conduzido a um estágio superior de organização da vida.

Dizendo de outra maneira, há uma abissal contradição entre o desenvolvimento das forças produtivas e as relações sociais de produção, algo inclusive já sinalizado por Marx no antológico prefácio da Contribuição à crítica da economia política (MARX, 2008).

As mais indigestas formas de ataques à educação pública e ao processo de escolarização dos indivíduos podem ser vistas como determinações concretas da destruição das forças produtivas. Taxas de analfabetismo, impossibilidades de acesso e condições de permanência estudantil nos distintos níveis de escolarização; a falta de financiamento, cortes de verbas e contingenciamentos do investimento público direcionado às instituições de ensino; os ataques à liberdade de cátedra e à autonomia didática, pedagógica, patrimonial e de gestão das escolas e universidades públicas; desqualificações generalizadas do trabalho docente e desvalorização dos profissionais da educação; o abrupto rebaixamento, 
aligeiramento e esvaziamento da formação humana por meio de propostas curriculares e orientações legais da política educacional, por intermédio da vulgarização do conhecimento, do incentivo à destruição do pensamento e da razão crítica, ou ainda, pelo fomento ao obscurantismo beligerante (DUARTE, 2018), são exemplos das mais distintas formas de destruição das forças produtivas no âmbito da formação humana.

Ora, a formação coletiva da humanidade é uma necessidade para impulsionar o processo revolucionário. Trotsky (2011), em 1938, afirmou que a tarefa histórica do período de transição consiste em superar as contradições entre a maturidade das condições objetivas de superação do capital e a imaturidade das condições subjetivas da classe trabalhadora. Marx e Engels (2007), também, já haviam evidenciado em 1845/46 que não bastavam as condições objetivas, era preciso desenvolver as condições subjetivas para estimular o processo de transição para além do capital.

Em uma sociedade cujo processo de alienação se encontra em estágio avançado, defender a formação humana como necessária para impulsionar a transição é fundamental, no sentido de reconhecer que há uma relação dialética entre condições objetivas e subjetivas, e que não somos regidos por outras leis que não sejam produto das condições materiais de produção e reprodução da existência da humanidade ao longo do seu próprio desenvolvimento.

Deste modo, a transição se coloca como processo de mediação necessário, pois, se trata de desenvolver em uma realidade degenerada condições coletivas reais para transformar a possibilidade em realidade, mesmo que dentro de certos limites socialmente condicionados. E, a questão da formação humana é central para o desenvolvimento da possibilidade de superação das contradições do modo de vida atual.

Trotsky (2010a) defende três pré-requisitos como necessários ao desenvolvimento da transição ao socialismo, sendo que dois deles dependem centralmente do processo de formação humana. O primeiro é o desenvolvimento de condições objetivas, tratando-se do alto desenvolvimento das forças produtivas. O segundo, a existência de uma força social interessada e organizada, capaz de alterar as condições da realidade devido à sua própria situação de submissão. O terceiro fundamento é justamente a defesa da classe trabalhadora como esta força social, como classe dirigente do processo de transição, a classe que assume no capitalismo a função social que a burguesia cumpriu no processo de luta contra o feudalismo. 
Note-se que Trotsky (2010a, 2010b, 2011) está justamente defendendo a necessidade de construção da unidade em torno daquilo que mais possibilita avançar em direção ao desenvolvimento das condições subjetivas necessárias para impulsionar a possibilidade de superação do capital.

Para ele, fazer avançar o desenvolvimento das condições subjetivas significa, de um lado, a construção de organismos revolucionários por meio do fortalecimento de sindicados combativos, de organizações de trabalhadores autodeterminadas e da construção do partido revolucionário independente das classes opressoras. Mas, por outro, erigi-se a necessidade do desenvolvimento de uma classe consciente, com indivíduos atuando e intervindo na luta de classes com as máximas possibilidades de apreensão da realidade em pensamento, e isto diz respeito à transformação qualitativa da classe em si à classe para si. É preciso, nesse sentido, que o fator subjetivo se coloque em movimento. Tal qual sintetizou Gramsci (1978, p. 47):

A possibilidade não é a realidade, mas é, também ela, uma realidade: que o
homem possa ou não fazer determinadas coisas, isto tem importância na
valorização daquilo que realmente se faz. [...] Mas a existência das
condições objetivas - ou possibilidade, ou liberdade - ainda não é suficiente:
é necessária "conhecê-las" e saber utilizá-las. Querer utilizá-las.

E, com vistas a impulsionar o processo de avanço das condições subjetivas, julgamos imperioso compreender a atual política de formação de professores que está em curso no nosso país. É o que nos propomos a seguir, descortinando as 'bases' das novas diretrizes curriculares.

\section{As bases da nova BNC-Formação de Professores do MEC}

Com a aprovação da Resolução CNE/CP nº 02 de 20 de dezembro de 2019, intitulada Diretrizes Curriculares Nacionais para a formação inicial de professores para a educação básica, instituindo a Base Nacional Comum para a formação inicial de professores (BNCFormação), fica revogada a Resolução CNE/CP n 02 de 01 de julho de 2015, fixando-se o prazo de dois anos para sua implementação nas instituições que ainda não haviam implementado a 02/2015, e um prazo de três anos para aquelas que já haviam iniciado o seu processo.

Do ponto de vista da organização curricular cujos cursos devem se adequar, fica assim delimitada a formação: uma carga horária mínima de 3.200 horas, distribuída em três grupos distintos. O Grupo I, denominado de base comum de conhecimentos, com 800 horas, voltadas 
para os fundamentos da educação e suas articulações com sistemas e práticas educacionais. $\mathrm{O}$ Grupo II, delimitado como aprofundamento, com 1.600 horas, visando-se os objetos específicos dos componentes curriculares, unidades temáticas e áreas de conhecimento, incluindo-se competências e habilidades previstas na Base Nacional Comum Curricular (BNCC - educação básica). E o Grupo III, denominado de prática pedagógica, com 800 horas articuladas desde o primeiro ano de curso, sendo 400 horas para o estágio supervisionado e 400 horas para as práticas como componente curricular.

$\mathrm{Na}$ descrição dos três grupos aludidos é frequente a menção à BNCC da educação básica, com explícitas referências às competências e habilidades, aos indicadores de desempenho, à dimensão da prática no processo formativo e aos eixos estruturantes da própria BNCC, seja pela menção aos campos de experiência da educação infantil, seja pelos conteúdos, unidades temáticas e objetos de conhecimento do ensino fundamental e médio. Além disso, afirma-se poder haver aproveitamento da formação e de experiências anteriores.

Vale dizer que a atual resolução atinge duramente a autonomia das instituições universitárias quanto à suas propostas curriculares, uma vez que esta resolução é muito mais prescritiva do que a 02/2015 e, mais do que isso, constitui-se como um verdadeiro retrocesso em relação à de 2015 , ao eliminar das diretrizes a formação continuada e valorização dos profissionais do magistério, numa perspectiva que se tinha de tratar as diretrizes curriculares como uma ampla política nacional de formação dos educadores.

$\mathrm{Na}$ contramão das posições apresentadas pelos educadores e suas entidades na audiência pública de 08 de outubro de 2019 e, posteriormente, reforçadas pelo posicionamento de mais de 30 organismos da área educacional, o Conselho Nacional de Educação explicitou que está em sintonia com proposições de caráter neotecnicista, privatista e praticista, pois, referenciando-se exclusivamente nas determinações da BNCC para a Educação Básica, tais diretrizes da formação de professores restringem ainda mais a possibilidade da formação solidamente constituída no campo da educação, com seus fundamentos e teorias pedagógicas plenamente desenvolvidas ocupando o caráter de centralidade formativa.

Note-se que a proposta formativa instituída é principiada por dois aspectos centrais: $i$ ) Princípios da política da formação docente e ii) Princípios da organização curricular dos cursos de formação docente. Notoriamente, ambos amarrados à implementação da BNCC da educação básica, pressupondo aprendizagens essenciais e competências específicas em consonância com as competências gerais da BNCC. Conforme seu artigo $8^{\circ}$, parágrafo II, os 
cursos devem ter como fundamentos pedagógicos “[...] o compromisso com as metodologias inovadoras e com outras dinâmicas formativas que propiciem ao futuro professor aprendizagens significativas e contextualizadas em uma abordagem didático-pedagógicas alinhada com a BNCC" (BRASIL, 2019, p. 04).

Sendo assim, alude às competências profissionais docentes que, no documento, são compostas por três dimensões: a dimensão do conhecimento profissional, da prática profissional e do engajamento profissional, incluindo-se quatro competências específicas - em cada uma destas três dimensões - e respectivas habilidades.

São competências específicas da dimensão do conhecimento profissional: dominar os objetos de conhecimento e saber como ensiná-los; demonstrar conhecimento sobre os estudantes e como eles aprendem; reconhecer contextos e; conhecer a estrutura e a governança dos sistemas educacionais.

Já as competências específicas da dimensão da prática profissional estão assim delimitadas: planejar as ações de ensino que resultem em efetivas aprendizagens; criar e saber gerir ambientes de aprendizagem; avaliar o desenvolvimento do educando, a aprendizagem e o ensino e; conduzir as práticas dos objetos de conhecimento, das competências e habilidades.

Por fim, as competências específicas da dimensão do engajamento profissional aparecem como: comprometer-se com o próprio desenvolvimento profissional; comprometerse com a aprendizagem dos estudantes e colocar em prática o princípio de que todos são capazes de aprender; participar do projeto pedagógico da escola e da construção dos valores democráticos e; engajar-se profissionalmente com as famílias e com a comunidade.

Tais competências, por si só, já seriam um tanto quanto controversas, uma vez que pautar a formação de professores exclusivamente nelas pode configurar em estratégia de rebaixamento e esvaziamento da formação política e pedagógica dos futures professores. $\mathrm{O}$ problema se torna ainda maior quando, ao final da resolução, na forma de anexos, encontramse as habilidades respectivamente associadas a cada uma destas dimensões das competências específicas.

No âmbito destas habilidades é que se busca concretizar todos os fundamentos e princípios formativos já sinalizados ao longo do texto da BNC-Formação de Professores, tais como: a centralidade da formação alicerçada na prática e nas experiências de aprendizagem, o compromisso com as chamadas metodologias inovadoras, projetos interdisciplinares, flexibilização curricular, construção de itinerários formativos e projetos de vida dos estudantes, as matrizes de competências, a análise dos desafios da vida cotidiana, desafios 
pedagógicos encarados com base em evidências, capacidade de resolução de problemas por meio de soluções práticas, dentre outros.

É preciso dizer que a formação de professores pautada pela lógica das competências não se configura como uma novidade. Não obstante, tamanha é a sua - a lógica das competências - valoração nestas diretrizes para a formação de professores, que consideramos importante desmistificá-la.

Em primeiro lugar, importa reafirmar a explícita relação de continuidade entre as pedagogias ativas escolanovistas, o construtivismo piagetiano e a pedagogia das competências, em que se ressalta o lema de inspiração deweyana entorno da insígnia learning by doing (PERRENOUD, 1999a, 1999b; SCHÖN, 1987, 1997, 2000). Como os próprios autores sustentam, as fontes primárias e originárias desse movimento pedagógico contemporâneo crescente remontam a John Dewey, a Montessori, a Tolstoi, a Froebel, a Pestalozzi, e mesmo ao Emílio de Rousseau. Portanto, estamos aqui situados no âmbito das chamadas pedagogias do aprender a aprender (DUARTE, 2011).

Em segundo lugar, a lógica das competências (DELVAL, 1998; PERRENOUD, 1997, 1999a, 1999b, 2002) possui vinculação direta com os estudos sobre os saberes tácitos e a epistemologia da prática reflexiva (NÓVOA, 1997, PÉREZ-GOMEZ, 1997; SCHÖN, 1987, 1997, 2000; TARDIF, 2000, 2002), concebendo-se competência como sinônimo direto de mobilização de saberes, transferência de saberes para o agir imediato, desempenho satisfatório em situações de experiência real. Assim, é explicita a sua vinculação ao ideário do pragmatismo filosófico, constituindo-se num verdadeiro pragmatismo pedagógico, algo que, diga-se de passagem, remonta ao próprio Dewey, haja vista as influências do pragmatismo em sua formação (SAVIANI, 2009).

Por fim, necessário é reconhecer a fundamentação filosófica da pedagogia das competências: o enfoque do idealismo subjetivo kantiano, o qual baliza inclusive a perspectiva da epistemologia genética de Jean Piaget, lastro teórico do construtivismo em suas inúmeras vertentes.

Como se sabe, Immanuel Kant (1724-1804) foi um filósofo alemão considerado racionalista, mas, que desempenhou um importante papel na filosofia moderna ao ser o primeiro a buscar superar as cisões entre corpo e mente, razão e experiência. Assim, colocouse contrário ao chamado dogmatismo racionalista antecedente a ele, cujo entendimento era o de que a razão seria o único caminho para o conhecimento (ANDERY et al, 1999). 
Entretanto, em que pese buscar reconhecer a importância da experiência no exercício de conhecer, alegando ser ela - a experiência - fornecedora de referentes particulares ao conhecimento, os conceitos e o entendimento humano teriam procedência em categorias já constituídas a priori, antecedentes à própria experiência.

Conforme Kant (ANDERY et al, 1999), os objetos externos do mundo exterior apenas podem nos afetar em virtude de possuirmos uma faculdade inata denominada de sensibilidade, uma capacidade passiva de captação dos objetos por meio de representações diversas, intitulada por ele de formas inatas de sensibilidade, também chamada de intuição pura. A sensibilidade seria, pois, a faculdade das intuições, sendo ela um a priori do ser humano, precedendo qualquer experiência. Graças à intuição pura as impressões fornecidas pelas sensações dos objetos, que são diversas, podem ser ordenadas a partir da própria capacidade da mente.

Assim, se para Kant nenhum conhecimento suplanta a experiência, ao mesmo tempo, ele - o conhecimento - sempre será um a priori dela, determinando, inclusive, as formas de se pensar a experiência. Neste sentido, o mundo exterior só poderia produzir a matéria da sensação, mas é mente humana que já traz em si o ordenamento desta matéria no espaço e no tempo, formulando os conceitos pelos quais a realidade se torna compreensível.

Ou seja, aquilo que aparece na percepção, chamado por Kant de fenômeno, se constitui de duas faces: sujeito e objeto. Entretanto, há nesse enfoque filosófico relativa prevalência da 'mente' em relação ao objeto e, igualmente, um abissal impasse ou obstáculo para a construção do conhecimento objetivo. E é este o ponto crucial que gostaríamos de ressaltar, cujo elemento formativo carrega implicações para a formação de professores. Recorremos à Andery et al (1999, p. 350):

Considerando que os objetos nos aparecem em função do modo como afetam nossos sentidos, isto é, que os objetos são captados pelos seres humanos segundo as condições de sensibilidade, espaço e tempo, não intuímos as coisas tais como elas são em si mesmas, mas sim do modo como as conhecemos. Portanto, não conhecemos as coisas em si (noumeno), mas somente tal como elas nos aparecem (fenômenos).

Tendo isso em vista, e considerando que as sensações serão sempre produzidas pelos sujeitos particulares, caberá a elas - sensações - subsidiar a percepção acerca do objeto e pouco, ou nada, acerca daquilo que o objeto realmente é. Isso tem relevantes e severas implicações para o processo de inteligibilidade da realidade, uma vez que o conhecimento do 
real fica, neste sistema filosófico, limitado ao alcance das representações subjetivas dos nossos sentidos em geral.

Em decorrência daquilo que o próprio Kant (1974, p. 59) afirmou, "Não conhecemos [os objetos] senão o nosso modo de percebê-los, o qual nos é peculiar e não tem que concernir necessariamente a todo ente". Por essa via, Kant identifica o conhecimento com a imagem que a consciência produz, por meio da representação das sensações acerca do objeto percebido. Assim se constitui o idealismo subjetivo kantiano.

Verifique-se que tais preceitos filosóficos constituem a base de fundamentação da epistemologia genética de Jean Piaget, uma das fontes do construtivismo e que possui fortes aproximações com a pedagogia das competências. Na teoria piagetiana se perpetua o dualismo entre sujeito e objeto, não superado por Kant, o que se desdobra - no construtivismo pedagógico - nas cisões entre indivíduo e sociedade, ou ainda, natureza e cultura, subjacentes a uma concepção de ser humano substancialmente natural e individual, mas que, gradativamente e por força das propaladas interações com o meio, tende a se tornar social.

Note-se que Piaget (1983) aparentemente solucionou a relação aventada, por intermédio dos conceitos de assimilação, acomodação e adaptação que o mesmo desenvolveu à luz de preceitos epistemológicos e gnosiológicos, evidenciando sua concepção de desenvolvimento das estruturas lógicas do psiquismo humano graças às relações imediatas e sensíveis que o organismo individual pode estabelecer com o meio ambiente.

A perspectiva por ele defendida é a de que deva ocorrer uma adaptação do organismo ao meio, à medida que tal organismo é capaz de se equilibrar ou reequilibrar internamente a partir dos estímulos e interações com o meio, acomodando a realidade externa conforme esta vai sendo assimilada pelos esquemas mentais internos. Quanto mais exitoso esse processo, maior a capacidade de adaptação do organismo.

Resulta desta fundamentação teórica a tese da construção ou autoconstrução do conhecimento pelo indivíduo em particular, visto ser tal processo algo resultante da relação do sujeito (que constrói ou autoconstrói o conhecimento) com o meio. Por isso, também, a insígnia pedagógica de que o indivíduo aprende interagindo com o meio, sendo seu desenvolvimento produto daquilo que ele próprio vivencia, experiencia e vive. E, assim sendo, postula-se a secundarização ou negação da transmissão do conhecimento objetivo, visto ser este - o conhecimento - resultado dos interesses e experiências particulares e subjetivas de cada sujeito. Conforme afirmou o próprio Piaget (1983, p. 224-225): 
[...] por essa razão evidente que para que uma transmissão seja possível entre adulto e criança ou entre meio social e a criança educada, é necessário haver assimilação pela criança do que lhe procuram inculcar do exterior. Ora, uma assimilação é sempre condicionada pelas leis desse desenvolvimento parcialmente espontâneo [...]. A equilibração me parece o fator fundamental desse desenvolvimento [...]. O ideal da educação não é aprender ao máximo, maximalizar os resultados, mas é antes de tudo aprender a aprender; é aprender a se desenvolver e aprender a continuar a se desenvolver depois da escola.

Seria então preciso uma concepção educativa e, em última instância, uma política educacional orientadora e legitimadora da formação dos sujeitos que respaldassem três princípios basilares: a ideia de que o aluno é sujeito da aprendizagem e responsável por ela; uma concepção de escola que deva funcionar exclusivamente com fins de possibilitar aos alunos a reconstrução do conhecimento socialmente elaborado e; por fim, delegando ao professor o papel e a tarefa de organizar o ambiente, os contextos interativos, as situações de aprendizagem, suscitando uma relação ativa entre o sujeito aprendiz e o meio, com vistas à ocorrência dos processos de assimilação, acomodação e adaptação de seus esquemas internos, construindo representações formais do mundo exterior.

Note-se a íntima relação entre a epistemologia genética piagetiana e a filosofia idealista subjetivista de Kant. Por seu turno, cumpre também verificar a profunda equivalência entre a pedagogia das competências da BNC-Formação de Professores e tais fundamentos, conforme a análise apresentada. Tais diretrizes, ao enfatizar a valorização da dimensão experiencial e prática da aprendizagem, conferindo lugar de destaque àquilo que se chama transferência e mobilização de recursos para o agir com pertinência e eficácia em situações complexas (sinônimo de competência), apela para situações de aprendizagem que levem à construção do conhecimento, ao desenvolvimento de competências e habilidades por meio de resolução de problemas, tomada de decisões pessoais, processos investigativos criativos e metodologias ativas.

Reconfigurando o papel da escola e do professor, delineando diretrizes que esvaziam os currículos de sólidos conhecimentos historicamente sistematizados, rebaixando a formação dos professores, resta mesmo corroborar para que os alunos dos mais distintos cursos das instituições de ensino superior aprendam a aprender, sob um enfoque formativo cujo enriquecimento do padrão cultural dos futuros profissionais da educação resulta comprometido. 


\section{À guisa de considerações finais}

Finalizamos esta exposição almejando ter explicitado claramente os nexos e relações entre a crise estrutural do capital que hoje assola a humanidade, a destruição das forças produtivas e suas incidências no processo de formação humana com implicações nas condições subjetivas capazes de intervir na dinâmica da história.

A análise apreendida é a de que as novas diretrizes para os cursos de formação de professores, denominada de BNC-Formação, carrega em seu interior um conjunto de elementos que desqualificam, descaracterizam e esvaziam os currículos e o processo formativo. Tais diretrizes configuram-se na forma alienada e rebaixada pela qual, no interior do universo ideológico neoliberal do capitalismo em sua fase imperialista, busca-se aviltar as consciências e manipular as subjetividades dos indivíduos com proposições pedagógicas idealistas, pragmatistas e neoprodutivistas, como é o caso das pedagogias das competências.

A negação do saber objetivo, a descaracterização do papel da escola em transmitir esse saber nas suas formas mais desenvolvidas e a desvalorização do papel do professor como agente do ensino compõe o acervo estratégico da atual política educacional, com vistas ao empobrecimento da formação pedagógica e cultural dos futuros professores.

Conscientes disso, temos procurado construir uma forma de resistência ativa coletiva de enfrentamento a todas estas medidas de desmonte da educação pública e do ensino público superior. Nosso entendimento é o de que tal tarefa possui, pelo menos, dois elementos centrais.

O primeiro elemento está circunscrito ao plano pedagógico, cuja palavra de ordem, em última instância, é a de "escovar a contrapelo"8! Significa agir, no interior das instituições de ensino e outros espaços possíveis, para disputar cada elemento do processo formativo, seja na construção de projeto político-pedagógico, no desenvolvimento de projetos de ensino, pesquisa e extensão, nas atividades curriculares e extracurriculares, nos planejamentos de ensino e aulas desenvolvidas, lutando pela ampliação dos horizontes culturais dos alunos, pela elevação das suas capacidades de pensar e refletir a realidade, por um trabalho educativo que esteja dirigido para o efetivo desenvolvimento das individualidades como um todo.

A dimensão pedagógica é fundamental para a disputa da direção do processo formativo das novas gerações em tempos de transição. E, como tentamos demonstrar, tem

\footnotetext{
${ }^{8}$ Expressão proferida certa feita pela saudosa professora Maria Célia Marcondes de Moraes, também sendo utilizada com certa ocorrência no campo do marxismo.
} 
consequências vitais na incansável busca de se fazer avançar as condições subjetivas da história subjacentes à problemática da formação humana.

Ela - a luta pela dimensão pedagógica - deve nos fazer ter sempre no horizonte a busca pela concretização da mais bela conceituação de trabalho educativo formulada pelo professor Dermeval Saviani, cujo "ato é o de produzir, direta e intencionalmente, em cada indivíduo singular, a humanidade que é produzida histórica e coletivamente pelo conjunto dos homens" (SAVIANI, 2008, p. 13). Afirmamos, sem tergiversação, que lutar pela humanização dos indivíduos é, ao mesmo tempo, lutar contra o processo de destruição das forças produtivas.

O segundo elemento da resistência ativa se coloca no plano político, e nele se postula a necessidade do fortalecimento dos organismos de luta dos trabalhadores da educação de forma organizada, notadamente, a luta pela sobrevivência e conservação dos sindicatos como instrumento de defesa e conquista das reivindicações vitais para a existência digna de todos.

Ademais, é fundamental ampliarmos nossa capacidade de unidade política com demais setores populares na luta por uma educação pública, gratuita, laica e de qualidade, defendendo a ciência e a tecnologia, lutando contra a perspectiva de estrangulamento e do fim do financiamento público das instituições de ensino superior e da educação básica, construindo formas de mudar a correlação de forças tal qual ela se apresenta hoje, marcada pelo avanço do retrocesso e da destruição das poucas conquistas obtidas nos últimos 20 anos.

No âmbito deste fortalecimento, a unidade entre a dimensão política e pedagógica permite reconhecer que o enfrentamento pedagógico ao rebaixamento e esvaziamento da formação humana e dos currículos escolares pode e deve estar articulado à defesa política da revogação da BNC-Formação de Professores.

É de extrema importância defender o retorno e permanência da resolução CNE/CP n ${ }^{\circ}$ 02/2015 como referência para uma base comum formativa nacional. Tal resolução apresenta elementos significativos em defesa de uma política nacional de formação e valorização dos profissionais da educação e articula-se à proposição de formação defendida pela Associação Nacional pela Formação de Profissionais da Educação (ANFOPE).

Isso tudo para que possamos manter viva a perspectiva de futuro dos jovens e das novas gerações que conosco convivem diuturnamente nos bancos escolares, desejosos pela conquista de seus anseios populares de soberania nacional nos distintos setores da economia, do trabalho, da saúde, da educação, da cultura e do lazer. 


\section{REFERÊNCIAS}

ANDERY, M. A. et al. Para compreender a ciência: uma perspectiva histórica. 8. ed. Rio de Janeiro: Espaço e Tempo; São Paulo: EDUC, 1999.

ANTUNES, R. Os sentidos do trabalho: ensaio sobre a afirmação e a negação do trabalho. 9. reimpressão. São Paulo: Boitempo, 2007.

BRASIL. Censo 2010. Instituto Brasileiro de Geografia e Estatística. Disponível em: https://censo2010.ibge.gov.br/. Acesso em: 10 mar.2020.

BRASIL. Resolução CNE/CP nº 02, de 01 de julho de 2015. Define as Diretrizes Curriculares Nacionais para a formação inicial em nível superior (cursos de licenciatura, cursos de formação pedagógica para graduados e cursos de segunda licenciatura) e para a formação continuada. Ministério da Educação. Conselho Nacional de Educação. Conselho Pleno. Brasília: MEC, 2015.

BRASIL. Resolução CNE/CP nº2, de 20 de dezembro de 2019. Define as Diretrizes Curriculares Nacionais para a Formação Inicial de Professores para a Educação Básica e institui a Base Nacional Comum para a Formação Inicial de Professores da Educação Básica (BNC-Formação). Ministério da Educação. Conselho Nacional de Educação. Conselho Pleno. Brasília: MEC, 2019.

CHEPTULIN, A. A dialética materialista: categorias e leis da dialética. São Paulo: AlfaOmega, 1982.

DELVAL, J. Aprender a aprender. 7. ed. Campinas: Papirus, 1998.

DUARTE, N. Vigotski e o "aprender a aprender": crítica às apropriações neoliberais e pósmodernas da teoria vigotskiana. 5. ed. Campinas: Autores Associados, 2011.

DUARTE, N. O currículo em tempos de obscurantismo beligerante. Rev. Espaço do Currículo (online), João Pessoa, v.11, n.2, p. 139-145, mai./ago. 2018.

FERNANDES, F. Capitalismo dependente e classes sociais na América Latina. Rio de Janeiro: Zahar Editores, 1981.

FOSTER, J. B. A financeirização do capital e a crise. Revista Outubro, n. 18, p. 9-41, 2009.

FRIGOTTO, G. A relação do estrutural e do conjuntural na sociedade brasileira e os impasses e perspectivas da educação. Texto de subsídio para o XI Fórum Nacional de Educação com o XIV Seminário Regional de Educação Básica e O II Encontro Nacional do PIBIC. 04 nov. 2013. Disponível em: http://nucleopiratininga.org.br/a-relacao-do-estrutural-edo-conjuntural-na-sociedade-brasileira-e-os-impasses-e-perspectivas-da-educacao/. Acesso em: 02 mar.2020.

GRAMSCI, A. Concepção dialética da história. 2. ed. Rio de Janeiro: Civilização Brasileira, 1978. 
HARVEY, D. O enigma do capital: e as crises do capitalismo. São Paulo: Boitempo, 2011.

HAYEK, F. A. V. O caminho da servidão. Rio de Janeiro: Instituto Liberal, 1990.

HOBSBAWN, E. A era dos extremos: o breve século XX (1914-1991). São Paulo:

Companhia das Letras, 1995.

KANT, I. Crítica da razão pura e outros textos filosóficos. São Paulo: Abril Cultural, 1974.

LÊNIN, V. I. O imperialismo: fase superior do capitalismo. São Paulo: Nova Palavra, 2005.

MANACORDA, M. A. Marx e a pedagogia moderna. 2. ed. rev. Campinas: Alínea, 2010.

MARX, K. O Capital. Crítica da economia política. Livro 1. v.1. Rio de Janeiro: Civilização Brasileira, 2006.

MARX, K. Contribuição à crítica da economia política. 2. ed. São Paulo: Expressão Popular, 2008.

MARX, K. O Capital. Crítica da economia política. Livro I. v.2. Rio de Janeiro: Civilização Brasileira, 2011.

MARX, K.; ENGELS, F. A ideologia alemã. São Paulo: Boitempo, 2007.

MELO, A. A. S. de. A mundialização da educação. Maceió: Edufal, 2004.

MÉSZÁROS, I. A crise estrutural do capital. São Paulo: Boitempo, 2009.

MOLLO, M. de L. R. Crédito, capital fictício, fragilidade financeira e crises: discussões teóricas, origens e formas de enfrentamento da crise atual. Economia e Sociedade, Campinas, v. 20, n. 3, p. 449-474, dez. 2011.

MONTORO, X. A. Capitalismo y economia mundial: bases teóricas y análisis empírico para la compreensión de los problemas económicos del siglo XXI. 2. ed. Madrid: Instituto Marxista de Economía, 2016.

NÓVOA, A. (Org.). Os professores e a sua formação. 3. ed. Lisboa: Dom Quixote, 1997.

PÉREZ-GOMEZ, A. O pensamento prático do professor: a formação do professor como profissional reflexivo. In: NÓVOA, A. (Org.). Os professores e a sua formação. 3. ed. Lisboa: Dom Quixote, 1997, p. 95-114.

PERRENOUD, P. Práticas pedagógicas, profissão docente e formação: perspectivas sociológicas. 2. ed. Lisboa: Dom Quixote, 1997.

PERRENOUD, P. Formar professores em contextos sociais em mudança: prática reflexiva e participação crítica. Revista Brasileira de Educação, Belo Horizonte, n. 12, 1999a, p. 5-19.

PERRENOUD, P. Construir as competências desde a escola. Porto Alegre: Artmed, 1999b. 
PERRENOUD, P. A prática reflexiva no ofício de professor: profissionalização e razão pedagógica. Porto Alegre: Artes Médicas, 2002.

PIAGET, J. Problemas de psicologia genética. In: PIAGET, J. Os pensadores. São Paulo: Abril Cultural, 1983, p. 209-294.

SAVIANI, D. Pedagogia histórico-crítica: primeiras aproximações. 10. ed. Campinas-SP: Autores Associados, 2008.

SAVIANI, D. Escola e democracia. 41. ed. Campinas-SP: Autores Associados, 2009.

SCHÖN, D. Educating the reflective practitioner; Donald Schön's presentation to the 1987 meeting of the American Educational Research Association. Washington, DC, 1987.

Disponível em: http://educ.queensu.ca/ russellt/howteach/schon87.htm. Acesso em: 20 nov.2019.

SCHÖN, D. Formar professores como profissionais reflexivos. In: NÓVOA, A. (Org.). Os professores e a sua formação. 3. ed. Lisboa: Dom Quixote, 1997, p. 79-91.

SCHÖN, D. Educando o profissional reflexivo: um novo design para o ensino e a aprendizagem. Porto Alegre: Artes Médicas, 2000.

TARDIF, M. Saberes profissionais dos professores e conhecimentos universitários: elementos para uma epistemologia da prática profissional dos professores e suas conseqüências em relação à formação para o magistério. Revista Brasileira de Educação, Belo Horizonte, n. 13 , p. 5-24, 2000.

TARDIF, M. Saberes docentes e formação profissional. 7. ed. Petrópolis: Vozes, 2002.

TROTSKY, L. Balanço e Perspectivas. In: TROTSKY, L. A teoria da revolução permanente. São Paulo: Editora Instituto José Luiz e Rosa Sunderman, 2010a.

TROTSKY, L. Revolução Permanente. TROTSKY, L. In: A teoria da revolução permanente. São Paulo: Editora Instituto José Luiz e Rosa Sunderman, 2010b.

TROTSKY, L. Programa de Transição. In: MARX, K.; LÊNIN, V. I.; TROTSKY, L. O programa da revolução. São Paulo: Nova Palavra, 2011. 


\section{SOBRE OS AUTORES:}

\section{Tiago Nicola Lavoura}

Pós-doutor em Educação e Psicologia pela Faculdade de Psicologia e Educação da Universidade de Aveiro, Portugal (UA). Pós-doutor em Educação Escolar pela Faculdade de Ciências e Letras da Universidade Estadual Paulista (UNESP-Araraquara). Docente da Universidade Estadual de Santa Cruz (UESC). Professor do Programa de Pós-Graduação em Educação - Mestrado Profissional (UESC). Líder do Grupo de Estudos e Pesquisas em Formação Humana e Educação Física (GEPEFEF-UESC). E-mail: nicolalavoura @ gmail.com. iD http://orcid.org/0000-0003-4382-0415.

\section{Melina Silva Alves}

Doutora em Educação pela Faculdade de Educação da Universidade Federal da Bahia (UFBA). Docente da Universidade Federal da Paraíba (UFPB). Coordenadora do Laboratório de Estudos e Pesquisas em Educação Física, Esporte e Lazer (LEPELPB). E-mail: melinasalves@gmail.com.

iD http://orcid.org/0000-0002-0100-253X.

\section{Cláudio de Lira Santos Junior}

Pós-doutor em Educação Escolar pela Faculdade de Ciências e Letras da Universidade Estadual Paulista (UNESP-Araraquara). Docente da Universidade Federal da Bahia (UFBA). Professor do Programa de Pós-Graduação em Educação da UFBA. Coordenador do Laboratório de Estudos e Pesquisas em Educação Física, Esporte e Lazer (LEPEL-UFBA). Email: clirasjr@gmail.com

(iD http://orcid.org/0000-0001-7172-1823. 